\title{
STUDI ADAPTASI RUMAH VERNAKULAR KUTAI TERHADAP LINGKUNGAN RAWAN BANJIR DI TENGGARONG
}

\author{
HIDAYATI, Zakiah ${ }^{1}$ and HS, Cisyulia Octavia ${ }^{2}$ \\ ${ }^{1,2}$ Program Studi Arsitektur, Politeknik Negeri Samarinda \\ Jl. Cipto Mangunkusumo Samarinda \\ Email: zakitec@yahoo.co.id
}

\begin{abstract}
ABSTRAK
Rumah vernakular Kutai tumbuh dalam tradisi Kutai di Kalimantan Timur. Rumah ini tersebar di Kabupaten Kutai Kartanegara (Kukar). Lokus penelitian adalah Tenggarong yang termasuk dalam salah satu kecamatan di Kukar. Kukar kini menjadi wilayah yang sering terkena banjir terutama pada musim hujan. Perubahan iklim dan kerusakan lingkungan menjadikan banjir semakin parah, tetapi rumah vernakular Kutai tetap kokoh berdiri. Bagaimana rumah vernakular Kutai beradaptasi di wilayah yang rawan banjir adalah tujuan penelitian ini. Metode penelitian adalah dengan menganalisis struktur dan konstruksi rumah vernakular Kutai, dari masa awal pembuatan rumah dan masa terkini. Jadi bukan mengkronologikan perkembangan teknik, bentuk atau material rumah vernakular Kutai dalam kurun waktu tertentu. Hasil penelitian yaitu terdapat beberapa jenis adaptasi yang bertahan sejak awal pembuatan rumah dan adaptasi baru untuk mempertahankan keberadaan rumah vernakular Kutai.
\end{abstract}

Kata kunci: Adaptasi, rumah, vernakular, banjir.

\begin{abstract}
Kutai vernacular houses represent Kutai tradition in East Kalimantan. Kutai Vernacular Houses are spread over Kabupaten Kutai Kartanegara (Kukar). It is closely related to the culture of majority in Kukar. The locus of the research is Tenggarong, a sub-district of Kukar. Kukar now faces flood due to rainy season. Both climate change and environmental impact raise the water level, but Kutai vernacular houses are still exist. How the Kutai vernacular houses addapt in flood zone is the aim of the research. The research method is analyzing the changes of structure and construction of Kutai Vernacular Houses, from the beginning of the house built to the latest condition. The conclusion: there are some long lasting adaptation while others are newer adjustments in order to keep Kutai Vernacular Houses survived.
\end{abstract}

Keywords: Adaptation, house, vernacular, flood.

\section{PENDAHULUAN}

Arsitektur vernakular adalah arsitektur yang tumbuh dari tradisi rakyat (folk tradition). Arsitektur ini tak memerlukan desainer, artis atau arsitek untuk merancang bangunan, ia tumbuh dari hasil terjemahan nilai budaya setempat ke dalam bentuk fisik oleh rakyat. Nilai arsitektur ini justru lebih terlihat pada proses desain (design process). Proses desain yang terjadi sangat variatif dan lebih individual (tergantung dari status ekonomi masyarakat, family requirements, maupun kondisi iklim setempat) (Rapoport, 1969).

Arsitektur vernakular adalah salah satu dari sekian banyak kekayaan budaya Indonesia. Arsitektur vernakular antar daerah di Indonesia memiliki kekhasan masing-masing. Perbedaan ini dipengaruhi oleh iklim, geografi, sumbar daya, material dan lainlain. Kalimantan Timur memiliki arsitektur rumah vernakular yang berakar dari budaya Kutai yang termasuk budaya tertua di Kalimantan Timur. Arsitektur vernakular Kutai merujuk pada rumah-rumah rakyat suku Kutai yang banyak terdapat di daerah Kutai (antara lain adalah Kabupaten Kutai Kartanegara, Kutai Timur dan Kutai Barat). Lokus penelitian ini adalah kecamatan Tenggarong yang pada masa lampau pernah menjadi pusat pemerintahan Kerajaan Kutai Islam.

Tenggarong berada di wilayah Kutai Kartanegara (Kukar) yang kini rawan banjir yang disebabkan oleh perubahan iklim dan kerusakan lingkungan hidup. Penyebab banjir adalah erosi dan sedimentasi, curah hujan yang tinggi, saluran drainase yang tidak memadai, fisiografi, kapasitas sungai dan air pasang (Kodoatie, 2002). Bencana alam yang menimpa Kecamatan Tenggarong tak bisa dilepaskan dari bencana alam yang menimpa kecamatan lain di Kutai 
Kartanegara. Banjir adalah bencana lingkungan yang rutin menimpa Kecamatan Tenggarong. Beberapa bencana lain seperti angin puting beliung juga pernah dialami tetapi sangat jarang terjadi.

Rumah vernakular Kutai masih cukup kokoh berdiri walau sudah berusia puluhan hingga ratusan tahun. Rumah vernakular Kutai dapat bertahan karena melakukan berbagai macam adaptasi di wilayah yang rawan banjir. Bentuk adaptasi rumah vernakular Kutai inilah yang menjadi fokus dalam penelitian.

Fokus penelitian cukup spesifik dan belum pernah diteliti dengan lokus yang sama. Secara tematik, penelitian yang berkaitan dengan rumah vernakular dengan lokus di pulau Jawa, Sumatra dan lain-lain, yang dikaitkan dengan bencana lingkungan seperti gempa - cukup sering dilakukan dan telah dipublikasikan secara luas. Sementara penelitian rumah vernakular Kutai dikaitkan dengan bencana lingkungan (banjir) belum pernah dilakukan dalam publikasi ilmiah

Adaptasi adalah kemampuan beradaptasi. Dalam buku Environment and Culture, Volume 1 (Altman, Rapoport, \& Wohlwill., 1980), pengertian adaptasi adalah pengurangan ketidaksesuaian dalam suatu sistem. Ada tiga strategi adaptasi yaitu adaptation by adjustment (adaptasi dilakukan dengan mengurangi konflik antara perilaku dan lingkungannya). Bentuk adaptasi ini adalah adaptasi yang paling harmoni dengan lingkungan, adaptation by reaction (adaptasi dilakukan dengan penentangan terhadap lingkungan, tidak melalui penyesuaian melalui tingkah laku), adaptation by withdrawal (adaptasi ini berupa penghilangan tekanan-tekanan dari area adaptif atau penarikan diri dari suatu lingkungan).

Lingkup adaptasi rumah vernakular Kutai yang diteliti adalah berupa adaptation by adjustment. Adaptasi ini dilakukan untuk menyelesaikan masalah yang dihadapi dengan menyesuaikan diri dengan lingkungan. Ketika lingkungan terus berubah, tentu rumah vernakular harus melakukan penyesuaian agar dapat bertahan.

Kearifan lokal arsitektur vernakular tercermin melalui kemampuan dalam menghadapi dan memecahkan problem yang dihadapinya. Problem dapat berupa bencana alam yang rawan dihadapi. Bencana alam yang umumnya terjadi di Indonesia adalah gempa, tanah longsor, dan banjir. Kearifan arsitektur vernakular Indonesia dalam menghadapi bencana di wilayahnya, cukup banyak diteliti oleh peneliti dari dalam maupun luar negeri.

Salah satu bentuk kearifan lokal dari arsitektur vernakular dijelaskan dalam Jurnal Dimensi Arsitektur Volume 35 No 1 (Gayatri \& Purwanto, 2007), bahwa arsitektur vernakular Nabire menjadi konsep rumah tinggal bagi pembangunan kembali rumah tinggal atau bangunan yang roboh dan rusak akibat bencana alam yang terjadi pada Februari 2004 dan November 2004. Arsitektur vernakular Nabire dianggap layak menjadi konsep rumah tinggal cepat dibangun karena bentuk konstruksi dan arsitekturnya sudah menjadi bagian dari kehidupan masyarakat Nabire. Arsitektur vernakular Nabire memiliki konstruksi yang mampu bertahan terhadap gempa, dan apabila konstruksi rusak tidak mengalami kerusakan yang terlalu parah. Konstruksi bangunan yang berbeda dari konstruksi vernakular Nabire, ternyata mengalami kerusakan yang jauh lebih parah dibandingkan dengan arsitektur vernakular. Hal ini karena arsitektur vernakular dibangun mengikuti sifat kelokalan wilayah yang dimiliki daerah Nabire seperti cuaca, angin, hujan,dan panas.

Dalam jurnal Dimensi Universitas Petra Vol 35, No 1 (Prihatmaji, 2007), dijelaskan bahwa rumah tradisional Jawa yang berada di daerah gempa III (gempa sedang) memiliki konstruksi bangunan tahan gempa. Struktur inti rumah Joglo adalah struktur kayu rong-rongan yang akan menahan gaya lateral, didukung oleh fleksibilitas, redaman, stabilitas, elastisitas, daktilitas, kehiperstatisan kayu dan konstruksi. Sistem tumpuan yang bersifat sendi dan atau rol, sistem sambungan lidah alur, konfigurasi soko-soko emper terhadap soko guru dan kekakuan soko guru oleh tumpang sari/brunjung dipandang sebagai kesatuan sistem earthquake responsive building. Hasil penelitian menunjukkan bahwa, struktur rumah Joglo aman untuk daerah zona gempa 3 (apabila sistem tumpuan dibuat jepit).

Oleh Pudjisuryadi dkk. (2007), dibuktikan dengan SAP 2000 dan RESMAT bahwa rumah Nias terbukti stabil dalam mengurangi beban internal pada saat gempat berlangsung. Dari Widosari (2010) dihasilkan kesimpulan penelitian bahwa rumah (rumoh) Aceh dapat bertahan dari gempa karena strukturnya yang saling mengunci dan rigid. (Widosari, 2010).

Dari beberapa jurnal di atas, beberapa metode yang berbeda dapat diaplikasikan dalam tema penelitian yang sama. Hasil umum yang dicapai dari beberapa penelitian di atas bahwa rumah vernakular adalah rumah yang sesuai dengan karakter masyarakat setempat dan memiliki adaptasi yang baik di wilayah tertentu dalam menghadapi bencana alam. Demikian pula rumah vernakular Kutai terlihat memiliki adaptasi yang baik di wilayah yang rawan banjir karena dapat bertahan selama puluhan hingga ratusan tahun.

\section{METODE PENELITIAN}

Penelitian ini menggunakan metode kualitatif dalam paradigma rasionalistik. Strategi metode kualitatif dipilih karena adaptasi struktur dan konstruksi 
rumah vernakular berorientasi 'proses', merupakan kegiatan eksplorasi, dan analisis dibentuk dari katakata secara deskriptif.(Norman K. Denzin, Yvonna S. Lincoln, 2000). Penelitian ini berlangsung selama lima bulan dari bulan Juni 2013 - November 2013. Pengamatan dilakukan pada 3 sampel rumah terpilih dengan kriteria berupa rumah rakyat, berusia tua (lebih dari 4 generasi, berusia lebih dari 80 tahun) dan lebih muda (2-4 generasi, kurang dari 80 tahun), dan berada di dataran \& bantaran sungai. Metode pengumpulan data adalah melalui wawancara, observasi dan studi pustaka. Sampel rumah dimodelkan dalam bentuk rangka struktur, dalam bentuk awal dibangun dan perubahan terkini. Di bagian ini, proses wawancara sangat penting dilakukan terutama pada penghuni dan tetangga sekitarnya. Observasi bangunan juga menjadi tantangan karena kondisi tanah di bawah panggung semakin tinggi akibat sedimentasi dan di sampel rumah lainnya, justru semakin terkikis oleh erosi.

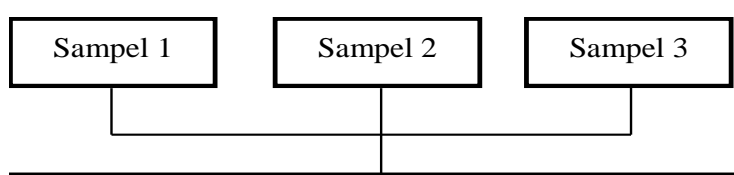

Semua sampel dimodelkan dalam bentuk rangka rumah, dari masa awal dan perubahan terkini. Datadata didapat dari wawancara, pengamatan dan studi pustaka

Analisis berdasar letak rumah, bentuk adaptasi yang terjadi, dan bencana banjir

\section{Gambar 1. Proses analisis}

Penelitian dilakukan di kawasan permukiman rumah vernakular Kutai yang banyak terdapat di seberang jalan raya tepi sungai Mahakam (kawasan Jalan Mangkurawang) dan di bantaran sungai Tenggarong yang berada dalam wilayah Kecamatan Tenggarong.

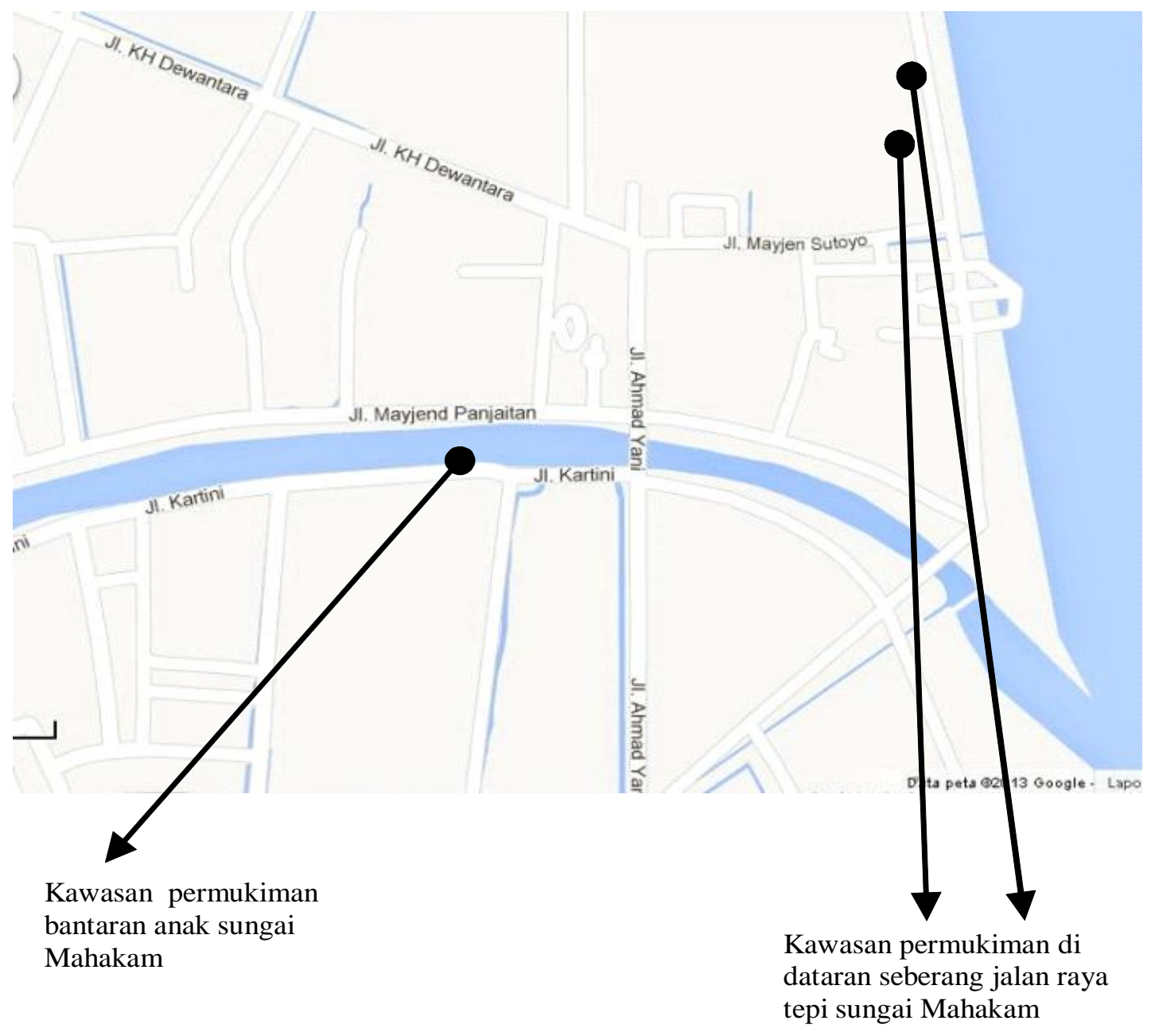

Gambar 2. Peta kawasan penelitian 


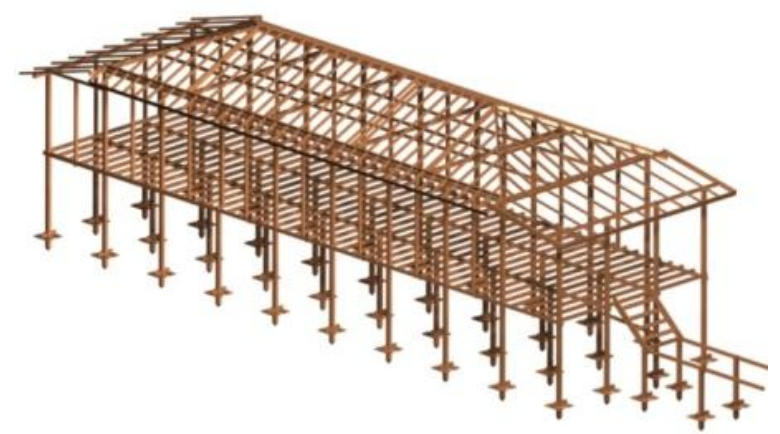

Gambar 3. Sampel 1 rangka rumah vernakular Kutai (masa awal)

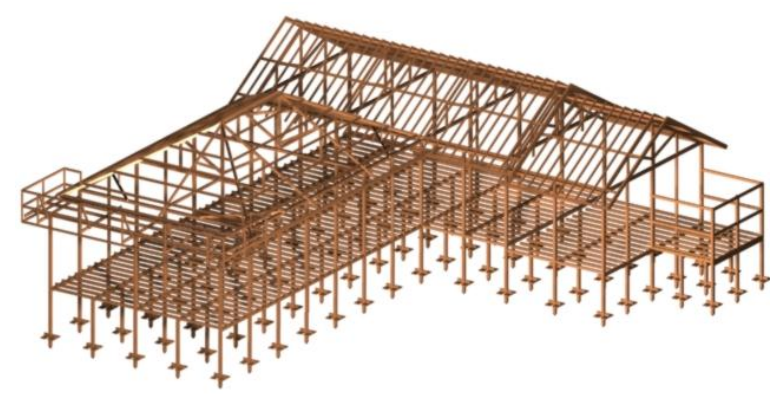

Gambar 4. Sampel 2 rangka rumah vernakular Kutai (masa awal)

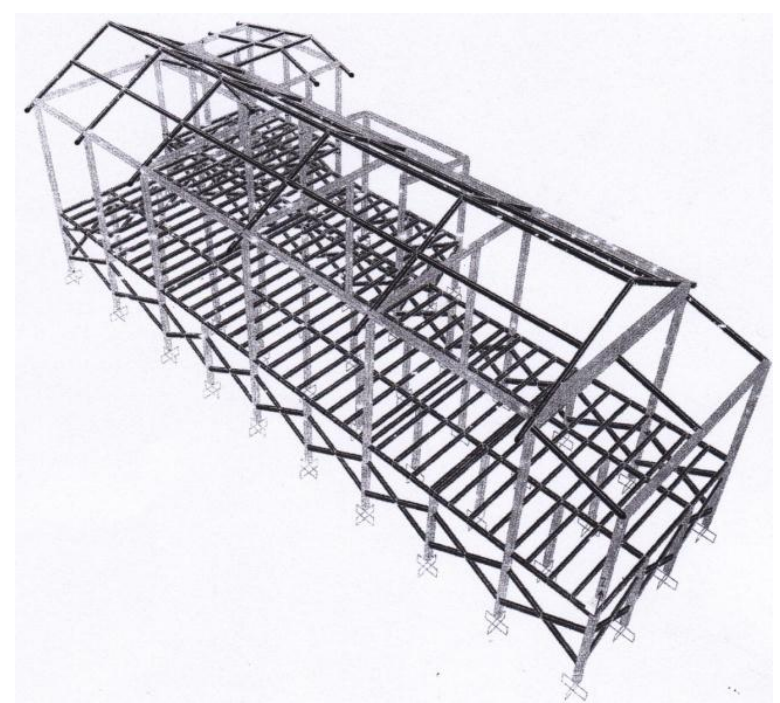

Gambar 5. Sampel 3 rangka rumah vernakular Kutai (masa awal)

\section{HASIL DAN PEMBAHASAN}

Dari catatan bencana di Tenggarong, bencana banjir adalah yang paling banyak terjadi di wilayah ini. Berikut adalah analisis penyebab banjir di Tenggarong:

- Erosi \& sedimentasi

Kondisi erosi \& sedimentasi di bantaran sungai Mahakam (membelah Kutai Kartanegara) dan sungai Tenggarong (membelah kota Tenggga- rong) dipengaruhi oleh kegiatan dan kualitas DAS Daerah Aliran Sungai) Tenggarong. Apabila ada kegiatan di suatu DAS maka kegiatan tersebut dapat mempengaruhi aliran air di bagian hilir, baik dari segi kuantitas maupun kualitas. Penebangan hutan secara sembarangan di bagian hulu suatu DAS dapat mengganggu distribusi aliran sungai di bagian hilir. Pada musim hujan air sungai akan terlalu banyak bahkan sering menimbulkan banjir tetapi pada musim kemarau jumlah air sungai akan sangat sedikit atau bahkan kering. Di samping itu kualitas air sungai pun menurun, karena sedimen yang terangkut akibat meningkatnya erosi cukup banyak (Sinukaban, 2007).

- Curah hujan

Iklim wilayah Kabupaten Kutai Kartanegara sangat dipengaruhi oleh iklim tropis basah yang bercirikan curah hujan cukup tinggi dengan penyebaran merata sepanjang tahun, sehingga tidak terdapat pergantian musim yang jelas. Kondisi iklim ini dipengaruhi oleh letak geografis, yakni iklim hutan tropika humida dengan suhu udara rata-rata $26^{\circ} \mathrm{C}$. Jumlah curah hujan wilayah ini berkisar 2.000-4.000 mm/tahun dengan jumlah hari hujan rata-rata 130-150 hari/tahun. (Kukar B., 2005).

- Fisiografi

Dari peta fisiografi Kutai Kartanegara, Kecamatan Tenggarong didominasi oleh lahan rawa pasang surut (BAPPEDA Kukar \& PUSPICS UGM, 2004). Wilayah rawa pasang surut masih termasuk Daerah Aliran Sungai bagian bawah, namun posisinya lebih ke dalam ke arah daratan, atau ke arah hulu sungai. Di wilayah ini energi sungai, berupa gerakan aliran sungai ke arah laut, bertemu dengan energi pasang surut yang umumnya terjadi dua kali dalam sehari (semi diurnal). (Subagyo, 2006).

- Kapasitas sungai Mahakam

Kapasitas sungai Mahakam semakin berkurang karena berbagai hal antara lain karena erosi dan sedimentasi yang berlebihan. Sedimentasi berhasil mendangkalkan sungai Mahakam sekitar $15 \mathrm{~cm}$ per tahun. Kedalaman sungai paling tinggi 36 sampai 37 meter. Pengukuran dilakukan pada kondisi air pasang dan kemungkinan akan lebih dangkal dalam kondisi air surut. Kedalaman tepi sungai yang terekam hanya hanya 14 meter. Penebangan hutan besar-besaran memicu erosi dan sedimentasi dengan volume lumpur sekitar 400 ton setiap tahun. Dampak pendangkalan dan pengurangan debit air dapat menyebabkan intrusi air laut ke arah Sungai Mahakam. (Tambunan, 2013). 
Kapasitas sungai Mahakam tentu berpengaruh ke kapasitas anak sungainya, termasuk di dalamnya adalah sungai Tenggarong. Sungai Tenggarong menjadi bertambah dangkal sehingga kapasitasnya menjadi berkurang dalam menampung luapan air sungai.

- Kapasitas drainase

Drainase kota Tenggarong saat ini tidak dapat menerima luapan air pasang sungai Mahakam dan curah hujan yang tinggi secara terus menerus, hal ini mengakibatkan kota Tenggarong sering terendam banjir. Kondisi drainase sering tertutup sedimentasi dan sampah. Buruknya drainase kota Tenggarong salah satunya adalah karena pengerjaan drainase yang sepotong-sepotong, tidak menyeluruh. Hal ini disampaikan oleh Anggota DPRD Kukar, Max Donald Tindage yang menilai perencanaan normalisasi drainase di Kota Tenggarong kurang cermat dan belum tertata dengan baik.

- Pengaruh air pasang

Pengaruh air pasang sungai Mahakam menyebabkan aliran dari anak sungai melambat. Bila banjir akibat curah hujan berlebihan dan air pasang terjadi bersamaan, maka akan terjadi arus balik dan air meluber ke berbagai tempat, seperti drainase, jalan raya dan area permukiman penduduk.

\section{Adaptasi by adjustment}

Adaptasi by adjustment dilakukan dengan perbaikan fisik rumah. Adaptasi dapat terkait fungsi ruang, struktur dan estetika bangunan. Bentuk adaptasi dapat berupa perubahan fungsi ruang, penggantian material akibat material yang semakin langka, penyambungan material karena ukuran material yang bertambah pendek, penambahan elemen struktur dan non struktur, dan penyesuaian dengan lingkungan fisik yang berubah (misalnya jalan raya yang semakin tinggi).

Gambar di bawah ini adalah contoh bentuk adaptasi berupa penambahan balok suai (kiri) dan memanfaatan air menggenang di kolong panggung dengan memelihara ikan (kanan).

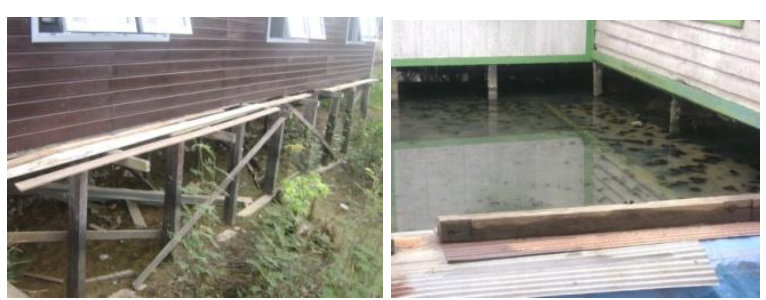

Gambar 6. Contoh adaptasi penghuni terhadap rumah vernakular

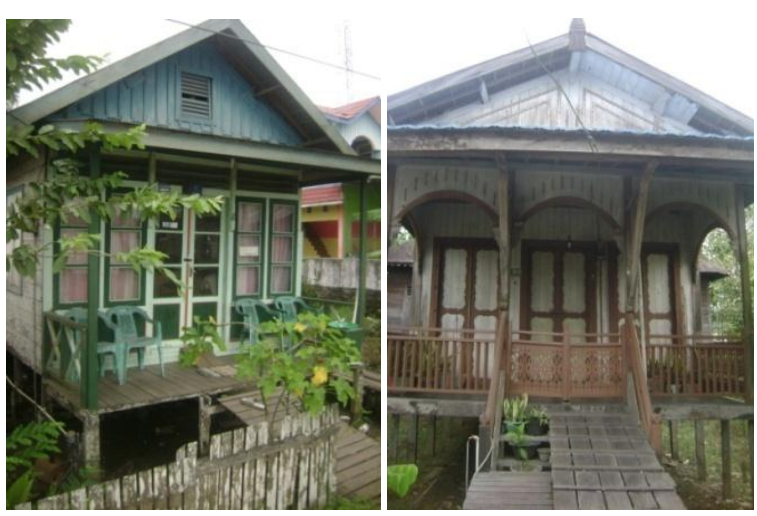

Gambar 7. Contoh rumah vernakular Kutai

\section{Struktur dan Konstruksi}

Secara garis besar rumah vernakular Kutai di Tenggarong berada di bantaran sungai Mahakam \& sungai Tenggarong dan dataran seberang jalan raya di tepi sungai Mahakam dalam kecamatan Tenggarong. Kondisi tanah adalah tanah rawa pasang surut. Rumah vernakular Kutai berbentuk panggung segiempat memanjang ke belakang. Sisi depan fasad rumah lebih pendek dibandingkan sisi samping rumah. Lebar rumah awalnya hanya sekitar 5 meter. Penambahan luasan rumah umumnya dilakukan di sisi kanan atau kiri rumah, dengan panjang ruang yang lebih pendek dari panjang rumah lama. Jika tambahan ruang berada dalam struktur atap yang sama maka disebut rumah gajah manyusu sedang bila atap ruang tambahan lebih rendah dari atap utama maka disebut koyo meraung.

\section{Struktur dan Konstruksi Bawah (Panggung)}

Pada rumah vernakular Kutai, panggung menyatu dengan pondasi rumah dan dahulu dapat dimanfaatkan untuk aktivitas penghuni seperti bersantai, menyimpan peralatan, memelihara ikan dan lain sebagainya. Pondasi rumah vernakular Kutai berupa batang/kolom ulin yang ditanam dengan jarakjarak tertentu sekitar 1.5-2 meter. Tiang ulin berukuran tanpa dimensi yang tersandardisasi seperti yang kita temui sekarang di pasaran. Dalam satu rumah, ukuran tiang panggung beraneka ragam misalnya $8 / 12,8 / 15,5 / 10,8 / 20$. Ukuran-ukuran tiang tercipta dari peralatan pemotong kayu yang sederhana, bahkan dalam satu tiang ulin bagian atas dan bawah pun terdapat selisih dimensi.

Tiang panggung ditancapkan dengan kedalaman tertentu hingga tercipta ruang panggung dengan tinggi ruang yang dapat dimanfaatkan untuk aktifitas penghuni. Tanah rawa pasang surut tidak memungkinkan untuk menancapkan tiang ulin hingga tanah keras. 
Konstruksi kalang sunduk pun digunakan untuk menahan tiang panggung agar tetap stabil di tempatnya. Kalang sunduk ditempatkan di tiap titik tiang panggung dengan panjang sekitar $50 \mathrm{~cm}$. Kalang dibuat dari balok atau papan ulin. Pada rumah vernakular yang lebih muda, kalang sunduk ditempatkan secara menerus, bukan titik lagi.

Awalnya semua rumah vernakular Kutai tidak menggunakan balok suai di tiang panggungnya. Kini balok suai dipasang di semua sisi luar tiang panggung sebagai bentuk adaptasi terhadap lingkungan yang semakin rusak. Tiang-tiang panggung terus menerus harus menahan hempasan air sungai dan terdorong oleh pergerakan tanah/lumpur dan sampah padat lainnya. Untuk menguatkan tiang panggung maka ditambahkan balok suai. Balok suai berfungsi sebagai balok pengaku tiang panggung yang sering terkena pergerakan arus air sungai.

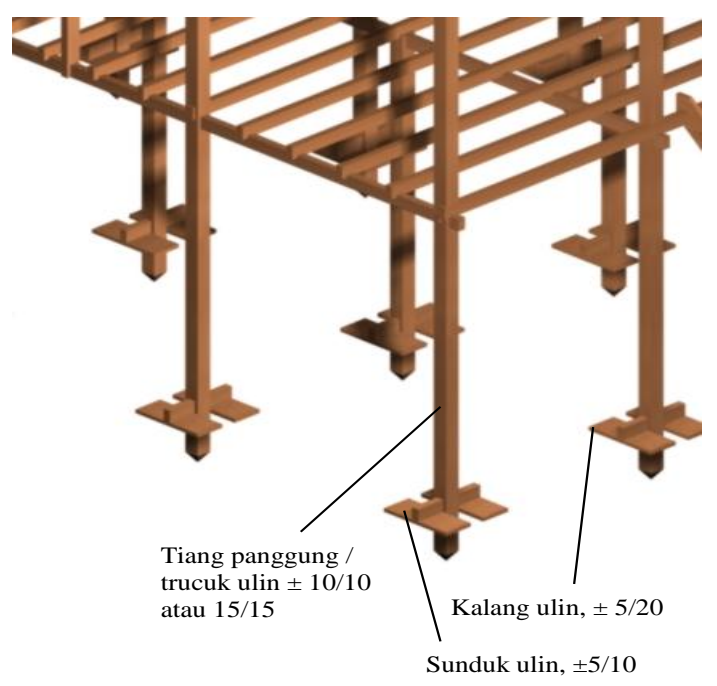

Gambar 8. Pondasi awal rumah vernakular Kutai

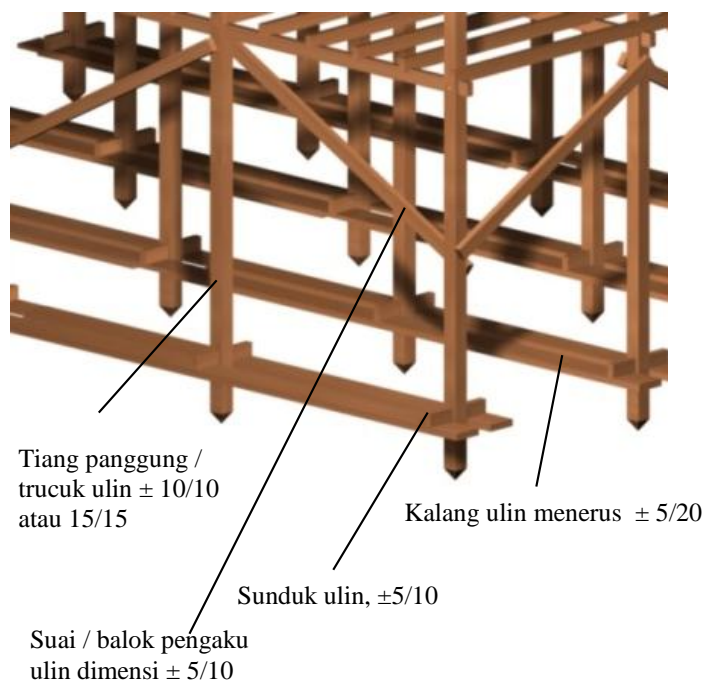

Gambar 9. Adaptasi pondasi rumah vernakular Kutai
Pada saat banjir pasang yang sering terjadi di Tenggarong, arus sungai tak hanya menumpukkan tanah, pasir atau batu (sedimentasi) di beberapa area bantaran sungai atau dataran tepi jalan raya, tetapi juga membawa sampah-sampah yang larut di sungai Mahakam dan sungai Tenggarong. Sebagian rumah vernakular, baik di tepi bantaran sungai Mahakam atau di dataran tepi jalan raya, membuat barikade panggung rumah dengan kayu, jaring atau batu agar sedimentasi dan sampah tak menumpuk di ruang dalam panggung. Barikade dibuat mengelilingi seluruh tepi panggung atau sebagian saja sesuai dengan arah kedatangan banjir.

Sloof panggung terdiri dari kombinasi balok lantai dan tiang panggung dari ulin. Balok lantai terdiri dari balok induk ukuran $\pm 10 / 10$ atau $5 / 10$ duduk di atas tiang panggung dengan ikatan sistem coak dan pasak sedangkan balok anak ukuran $\pm 5 / 10$ duduk di atas balok-balok induk dengan ikatan sistem coak dan pasak dengan jarak antara balok anak sekitar $40 \mathrm{~cm}$. Tiang panggung menghubungkan balok induk $( \pm 5 / 20)$ dan sunduk kayu ulin $( \pm 5 / 10)$.

Tangga menjadi salah satu elemen yang juga mengalami adaptasi. Kolong yang semakin pendek menyebabkan tangga sebagai penghubung antara panggung dan rumah menjadi berubah, awalnya tangga cukup tinggi dan kini menjadi semakin pendek. Konstruksi tangga terdiri dari tangga yang tinggi dan rendah. Konstruksi tangga yang tinggi menggunakan pasak dan papan ulin. Setiap anak tangga, pada kedua ujungnya dibentuk tonjolan sekitar $2 \times 2 \times 2.5 \mathrm{~cm}$ yang dimasukkan ke dalam lubang pada 2 papan yang mengapit anak tangga. Selanjutnya dikunci dengan pasak di lubang pada tonjolan kanan dan kiri dari anak tangga. Perlakuan berulang pada setiap anak tangga. Konstruksi pasak akan membuat tangga atau elemen bangunan lainnya menjadi terkunci.

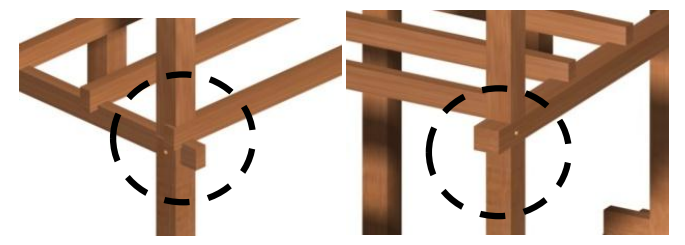

Gambar 10. Ikatan balok dan kolom

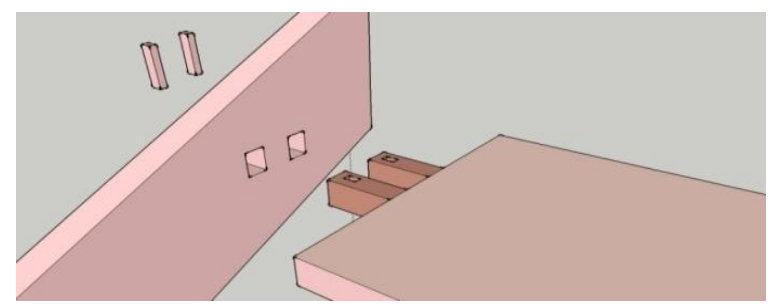

Gambar 11. Ikatan balok dan kolom 


\section{Struktur dan Konstruksi Atas (Ruang Hunian dan Atap)}

Struktur ruang hunian terbentuk dari sambungan kolom menerus vertikal dari sisi panggung terluar hingga ke ruang hunian dan teras. Ruangan terbagi teras, ruang los dan dapur. Pada perkembangannya ruang los kemudian disekat menjadi beberapa ruang seperti ruang tamu, ruang tengah dan kamar tidur. Sekat dinding menggunakan papan kayu.

Material penutup dinding berupa papan kayu ulin atau kapur yang tersusun secara vertikal dan horisontal. Bagian dinding yang terkena langsung dengan hempasan pasang sungai/hujan/banjir tersusun secara horisontal. Sedangkan bagian dinding rumah yang sedikit terlindungi oleh atap, papan dinding tersusun secara vertikal. Susunan pola papan dinding ini tidak berubah dan masih dapat beradaptasi dengan lingkungan terkini. Bentuk susunan horisontal dan vertikal ini berkaitan dengan penghindaran atau pengurangan akibat tempias hujan atau hempasan air sungai (jika sedang pasang atau luapan air sungai) yang mengenai dinding rumah.

Konstruksi apung pada WC yang terpisah dengan rumah utama di bantaran sungai adalah bentuk adaptasi yang baik dengan lingkungan yang rawan banjir. Pasang surut air tidak menenggelamkam WC. Sayangnya demi alasan kenyamanan, sebagian penghuni memindahkan WC ke bagian teras belakang sehingga menempel dengan rumah utama. Pergerakan air sungai sering mengenai dinding dan masuk ke bagian dalam WC apung. Sementara WC rumah vernakular di dataran, tidak menggunakan konstruksi apung tetapi WC permanen yang menempel dengan rumah utama.

Atap rumah vernakular Kutai di kecamatan Tenggarong umumnya berbentuk pelana dan limasan. Kemiringan atap sekitar 20 - 30 derajat. Kuda-kuda rumah vernakular Kutai terbuat dari kayu ulin yang kekuatannya dapat bertahan puluhan hingga ratusan tahun.
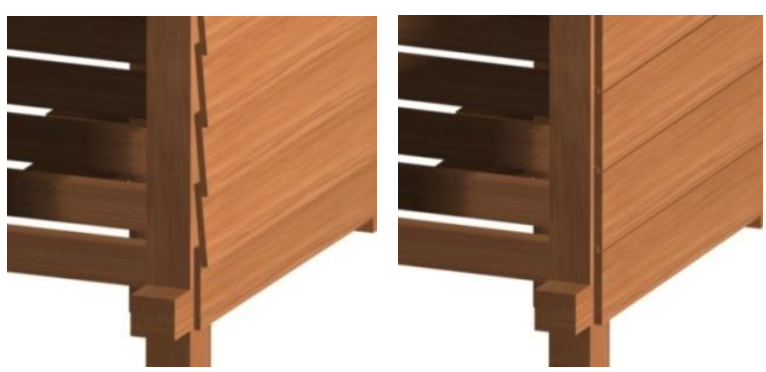

Gambar 12. Detil papan dinding kayu horisontal miring polos (kiri) dan alur lidah (kanan)

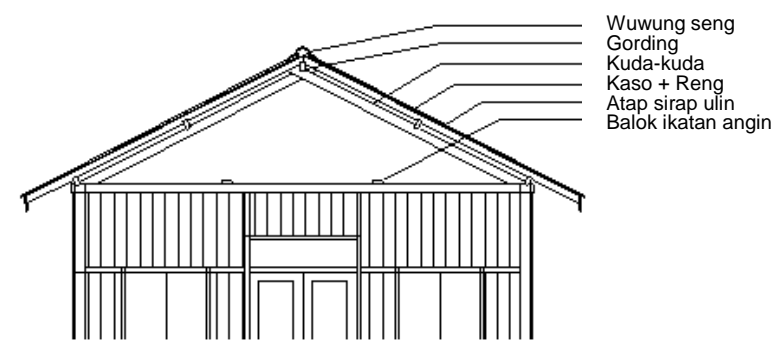

Gambar 13. Kuda-kuda tanpa sambungan

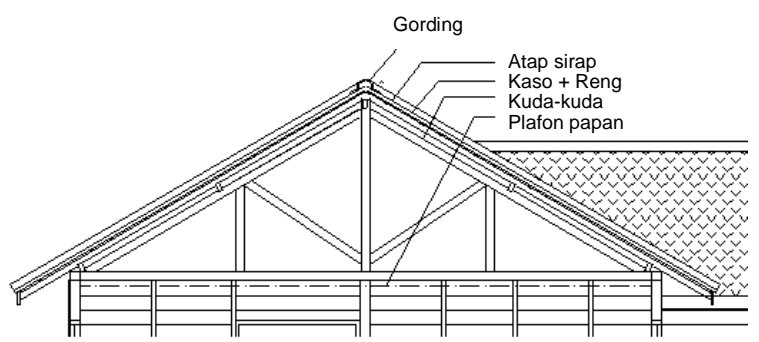

Gambar 14. Kuda-kuda dengan sambungan

Bentuk kuda-kuda rumah vernakular Kutai cukup unik dan berbeda dengan rumah vernakular lainnya. Bentuk kuda-kuda adalah segitiga dengan pasak di kedua sudut kanan kiri, tanpa ikatan pengaku dan sambungan kayu seperti umumnya rumah vernakular dari daerah lain. Pada masa lampau, panjang kuda-kuda $5 \mathrm{~m}$ tanpa sambungan. Kini panjang kayu ulin maksimal sekitar $4 \mathrm{~m}$ dan kudakuda harus disambung serta ditambah dengan balok vertikal di bagian tengah simetris kuda-kuda. Adaptasi konstruksi kuda-kuda ini dipengaruhi oleh faktor ketersediaan kayu ulin yang semakin lama semakin menipis.

Pada material penutup atap juga berubah. Dahulu semua atap rumah vernakular ditutup oleh sirap (papan tipis dari kayu ulin yang disusun bertumpuk), tetapi dalam perkembangannya sirap semakin sulit didapat karena kayu ulin mulai menipis dan sirap tak bertahan lama jika terus menerus terkena hujan. Sering sekali terjadi kebocoran atap pada rumah vernakular, yang juga menimpa kuda-kuda atap dan lantai-lantai kayu. Akhirnya rumah-rumah vernakular kemudian beradaptasi dengan menggunakan material seng bergelombang dianggap lebih tahan terhadap air hujan. Hasil analisis dapat dilihat pada tabel 1 .

Perubahan adaptasi struktur dan konstruksi rumah vernakular Kutai, umumnya tidak terjadi dalam jumlah yang tinggi. Perubahan yang terjadi rata-rata satu hingga dua macam, dari sejak rumah terbangun hingga kini. Misalnya pada material atap, perubahan terjadi dari atap sirap menjadi atap seng. 
Tabel 1. Bentuk adaptasi rumah vernakular Kutai di struktur bawah

\begin{tabular}{|c|c|c|}
\hline No & Bentuk awal & $\begin{array}{c}\text { Bentuk adaptasi yang } \\
\text { ditemukan }\end{array}$ \\
\hline \multicolumn{3}{|c|}{ Struktur bawah/panggung } \\
\hline & $\begin{array}{l}\text { Tiang-tiang } \\
\text { panggung }\end{array}$ & $\begin{array}{l}\text { Penambahan balok suai antar } \\
\text { tiang panggung }\end{array}$ \\
\hline 2. & Sisi ruang panggung & $\begin{array}{l}\text { Ditambah dengan papan ulin, } \\
\text { jala atau pondasi batu di sisi } \\
\text { tertentu dari panggung }\end{array}$ \\
\hline & Tangga & $\begin{array}{l}\text { Tangga dipertahankan tetapi } \\
\text { ketinggian tangga menuju ke } \\
\text { dalam rumah cenderung } \\
\text { semakin pendek (rumah di } \\
\text { dataran) atau semakin tinggi } \\
\text { (rumah di bantaran) } \\
\text { Konstruksi pasak pada tangga } \\
\text { tetap dipertahankan }\end{array}$ \\
\hline & Jembatan & $\begin{array}{l}\text { Salah satu sisi jembatan } \\
\text { bertambah tinggi mengikuti } \\
\text { level jalan raya yang semakin } \\
\text { tinggi }\end{array}$ \\
\hline & $\begin{array}{l}\text { Konstruksi kalang } \\
\text { sunduk kaki } \\
\text { panggung }\end{array}$ & $\begin{array}{l}\text { Kalang sunduk titik masih } \\
\text { dipertahankan. } \\
\text { Untuk rumah vernakular yang } \\
\text { lebih baru menggunakan kalang } \\
\text { sunduk menerus }\end{array}$ \\
\hline & $\begin{array}{l}\text { Konstruksi balok } \\
\text { lantai induk }\end{array}$ & $\begin{array}{l}\text { Tidak berubah. } \\
\text { Konstruksi balok lantai induk } \\
\text { dan tiang panggung dengan } \\
\text { sistem pasak }\end{array}$ \\
\hline
\end{tabular}

Tabel 2. Bentuk adaptasi rumah vernakular Kutai di struktur atas

\begin{tabular}{|c|c|c|}
\hline No & Bentuk awal & $\begin{array}{c}\text { Bentuk adaptasi yang } \\
\text { ditemukan }\end{array}$ \\
\hline \multicolumn{3}{|c|}{ Ruang hunian } \\
\hline \multicolumn{2}{|c|}{$\begin{array}{l}\text { 1. Posisi papan } \\
\text { penutup dinding }\end{array}$} & $\begin{array}{l}\text { Tidak berubah. } \\
\text { Papan vertikal pada area yang } \\
\text { cukup terlindungi atap dan } \\
\text { papan horisontal untuk area } \\
\text { dinding yang kurang terlindungi } \\
\text { dari tempias hujan yang tinggi }\end{array}$ \\
\hline & WC apung & $\begin{array}{l}\text { Ada yang berubah (WC apung } \\
\text { menjadi WC permanen) dan ada } \\
\text { yang tidak berubah. }\end{array}$ \\
\hline \multicolumn{3}{|c|}{ Struktur atas } \\
\hline & Kuda-kuda & $\begin{array}{l}\text { Awalnya semua kuda-kuda } \\
\text { tanpa sambungan ( } 5 \text { meter) dan } \\
\text { berbentuk segitiga tanpa balok } \\
\text { vertikal atau ikatan pengaku. } \\
\text { Kini masyarakat harus } \\
\text { menyambung kuda-kuda }\end{array}$ \\
\hline 4. & Atap sirap & $\begin{array}{l}\text { Sebagian besar telah mengganti } \\
\text { atap sirap dengan atap seng. }\end{array}$ \\
\hline
\end{tabular}

Hal ini menandakan rumah vernakular dibangun dengan pertimbangan yang matang disesuaikan dengan kondisi lingkungan, sehingga memiliki adaptasi yang cukup panjang.

\section{KESIMPULAN \& SARAN}

Adaptasi yang dilakukan oleh penghuni rumah vernakular Kutai adalah adaptasi by adjustment yaitu penyesuaian-penyesuaian fisik rumah untuk menghadapi lingkungan yang rawan banjir.

Bentuk perubahan adaptasi struktur dan konstruksi rumah vernakular Kutai untuk tiap bagian tidak terjadi dengan intensitas tinggi. Seringkali hanya terjadi satu hingga dua macam saja. Elemen struktur dan konstruksi yang masih kuat atau kokoh maka tradisi tersebut terus dipertahankan oleh masyarakat, seperti bentuk sambungan-sambungan antar elemen struktur.

Adaptasi terhadap lingkungan yang rawan banjir paling banyak dilakukan pada struktur bawah yang umumnya bersentuhan langsung dengan penyebab banjir. Berbagai adaptasi yang dilakukan adalah penambahan balok suai pada tiang panggung, meninggikan tiang panggung, penambahan papan ulin di hampir keliling panggung, tangga yang memendek, jembatan semakin meninggi di salah satu sisinya, perubahan konstruksi WC dan material penutup atap. Sedang elemen yang tidak berubah adalah konstruksi kalang sunduk pada pondasi, konstruksi pasak balok lantai induk \& tiang panggung, konstruksi pasak pada tangga dan posisi papan penutup dinding. Elemen yang tidak atau belum berubah ini bermakna memiliki nilai adaptif yang panjang dan bertahan puluhan bahkan ratusan tahun.

Sementara adaptasi konstruksi kuda-kuda dan susunan balok lantai tidak dipengaruhi langsung dengan penyebab banjir di Tenggarong. Adaptasi rumah vernakular Kutai juga dipengaruhi oleh kondisi lokasi. Terdapat sedikit perbedaan antara rumah di dataran dan di bantaran sungai. Dapat dikatakan bahwa struktur dan konstruksi rumah vernakular Kutai mampu beradaptasi dengan baik di lingkungan yang rawan banjir di Tenggarong.

Disarankan untuk pembangunan rumah panggung kayu di tanah rawa, agar dilakukan pemancangan kayu dengan tumbukan yang sama di setiap titik kolom agar daya dukung setiap kolom menjadi sama. Konstruksi kalang sunduk adalah konstruksi pondasi yang tepat di daerah rawa. Penambahan balok suai perlu dilakukan pada rumah-rumah panggung di wilayah yang rawan banjir dan tanah rawa karena dapat menguatkan bangunan. Sisi ruang panggung yang ditutup masif sebaiknya tidak dilakukan karena dapat menghambat aliran air sungai di bawahnya. Peninggian tiang panggung seluruh bagian rumah adalah bentuk adaptasi skala 'besar' yang dapat dilakukan untuk mempertahankan rumah-rumah kayu di lingkungan rawan banjir. 


\section{DAFTAR PUSTAKA}

Altman, I., Rapoport, A., \& Wohlwill., J. F. (1980). Human Behaviour and Environment. In J. Berry, Cultural Ecology and Individual Behaviour (p. 100). New York: Plenum Press.

BAPPEDA Kukar \& PUSPICS UGM. (2004). Sistem Informasi Wilayah dan Database Kabupaten Kutai Kartanegara. Tenggarong: BAPPEDA Kukar.

Gayatri, I. S., \& Purwanto, L. (2007). Arsitektur Vernakular Nabire dan Kondisi Nabire Pasca Gempa. Dimensi, 35(1).

Kabupaten Kutai Kartanegara. (2013, Mei 26). Retrieved Agustus 16, 2013, from Wikipedia: http://id.wikipedia.org/wiki/Kabupaten_Kutai Kartanegara

Kodoatie, R. J. (2002). Banjir,Beberapa Penyebab dan Metode Pengendaliannya dalam Perspektif Lingkungan. Yogyakarta, DIY: Pustaka Pelajar.

Kukar, B. (2005). Rancangan Akhir RPJPD Kabupaten Kutai Kartanegara 2005-2025. BAPPEDA Kutai Kartanegara.

Norman K. Denzin, Yvonna S. Lincoln. (2000). Handbook of Qualitative Research. California: Sage Publication.

Prihatmaji, Y. P. (2007). Perilaku Rumah Tradisional Jawa "Joglo" terhadap Gempa. Dimensi, 35(1), $1-12$.
Prijotomo, J., \& Adiyanto, J. (2004). Arsitektur Nusantara: menuju keniscayaan. Surabaya: Wastu Lanas Grafika.

Pudjisuryadi, P., Lumantarna, B., \& Y.Lase. (2007). Base Isolation in Traditional Building Lesson Learned From Nias March 28, 2005 Earthquake. EACEF-The 1st Int Conference of European Asian Civil Engineering Forum. 131, 242-247. Jakarta: Universitas Pelita Harapan.

Rapoport, A. (1969). House, Form, and Culture. New York: Prentice Hall.

Sinukaban, N. (2007). Peranan Konservasi Tanah dan Air dalam Pengelolaan Daerah Aliran Sungai. (Pengurus Pusat Masyarakat Konservasi Tanah dan Air Indonesia 2004-2007) Retrieved September 5, 2013, from bebasbanjir 2025: http://bebasbanjir2025.wordpress.com/04konsep-konsep-dasar/das-dan-pengelolaannya-2/ Subagyo. (2006). Lahan Rawa Pasang Surut. In B. P. Pertanian, Karakteristik dan Pengelolaan Lahan Rawa. Jakarta: Balai Besar Penelitian dan Pengembangan Sumberdaya Lahan Pertanian.

Tambunan, E. (2013). Darurat Transportasi Sungai Mahakam. Retrieved September 1, 2013, from Tubas media: http://www.tubasmedia.com/ berita/darurat-transportasi-sungai-mahakam/

Widosari. (2010). Mempertahankan Kearifan Lokal Rumoh Aceh dalam Dinamika Kehidupan Masyarakat Pasca Gempa dan Tsunami. Local Wisdom, 27-36. 